\title{
Seminario Interno de Profesores 2006
}

El Seminario Interno de los profesores de la Facultad de Teología, que se llevó a cabo en 11 sesiones de reflexión entre abril y noviembre de 2006, bajo el título "Que tengan vida en abundancia", se propuso abordar el tema de la vida como una forma de entrar en sintonía con la perspectiva del lema de la Quinta Conferencia del Episcopado Latinoamericano, cuyo trabajo de preparación se desarrolló en buena parte durante ese mismo año.

Cuatro de las ponencias del Seminario están recogidas en este número de Teología y Vida: "El concepto de "desarrollo integral" en la Doctrina Social de la Iglesia", del Prof. Patricio Miranda, "Celebración de la Vida en las comunidades de América Latina", del Prof. Guillermo Rosas, "De una vida amenazada a una vida anhelada. Atisbos a una teología de la vida en diálogo con la literatura", del Prof. Alberto Toutin, y "Vida y muerte", del Prof. Juan Noemi.

Ellas dan cuenta de la actualidad permanente del tema de la vida para la teología. La vida está, en cierto modo, siempre en el centro de toda reflexión teológica. "Yo vine para que tengan vida", dice el Señor, "y la tengan en abundancia" (Jn 10, 10). El misterio pascual de Cristo, que desencadena no solo el cristianismo, sino con él la razón de nuestra fe que a partir de la tumba vacía estamos llamados a dar en las circunstancias, posibilidades y condicionamientos de la cultura y la sociedad actuales, es esencialmente un misterio de vida, Vida plena y abundante en Cristo.

Esta misma publicación, que busca permanentemente dialogar con el mundo actual desde el acontecimiento Cristo, lleva por nombre "Teología y Vida", coincidiendo significativamente con el Seminario 2006, parte de cuyos frutos publicamos en este número. Esperamos que, en la perspectiva del importante encuentro de los obispos de nuestro continente latinoamericano, contribuyan a ahondar nuestra reflexión creyente para responder desde el Evangelio de Vida a los muchos y siempre nuevos desafíos de la hora actual. 
